\title{
Reliability and Validity of WATCH: Warwick Assessment InsTrument for Clinical TeacHing
}

\author{
Sonia ljaz Haider ${ }^{1}$, Khalid Masood Gondol ${ }^{2}$, Muhammad Tariq ${ }^{3}$, Muhammad Furqan Bari ${ }^{4}$ and Iqbal Azam ${ }^{5}$ \\ ${ }^{1}$ Department of Educational Development, Faculty of Health Sciences, The Aga Khan University, Karachi, Pakistan \\ ${ }^{2}$ Department of Surgery, King Edward Medical University, Lahore, Pakistan \\ ${ }^{3}$ Department of Medicine, Faculty of Health Sciences, The Aga Khan University, Karachi, Pakistan \\ ${ }^{4}$ Department of Pathology, Dow University of Health Sciences, Karachi, Pakistan \\ ${ }^{5}$ Department of Community Medicine, Faculty of Health Sciences, The Aga Khan University, Karachi, Pakistan
}

\begin{abstract}
Objective: To determine the reliability, validity, feasibility, acceptability and perceived educational impact of WATCH: Warwick Assessment insTrument for Clinical teacHing among doctors in Pakistan.

Study Design: Cross-sectional research study.

Place and Duration of Study: The College of Physicians and Surgeons, Pakistan, from September 2018 to August 2019.

Methodology: Postgraduate trainees were asked to rate the clinical teaching sessions, using WATCH, which consists of 15 items. Percentage was used to calculate gender and participation from different specialties. Inter-item correlations of 15 items with individual mean scores, standard deviations and Cronbach's Alpha were reported, including Friedman test, in order to observe the scores across multiple conditions. The Hotelling's $\mathrm{T}^{2}$ test was used to test whether the answers provided by the study participants to the questionnaire were equal. Construct validity was determined using factor analysis while feasibility, acceptability, and educational impact was evaluated by seeking participants' feedback on five semi-structured questions.

Results: More than $80 \%$ ranked WATCH from good to excellent. Oveall 8 items were perceived as excellent, while 7 items received rating of good. Inter-item correlation ranged from 0.61 to 0.81 . Cronbach Alpha was reported to be 0.975 , with significant difference in mean scores of different items (Friedman's Chi-Square $=4285.54 ; p<0.001$ ). The Hotelling's $T^{2}$ test ( 21598.871 with $\mathrm{F}=185.249, \mathrm{df}=14,2654 ; \mathrm{p}<0.001$ ) indicated that the mean values of the responses of different questions in the instrument were statiscally different. Factor analysis indicated one factor accounting for 73.97 of variance. The majority $(93 \%)$ of the participants found the instrument easy to complete, most participants $(91.5 \%)$ indicated it as an acceptable method of assessment, and majority $(90.8 \%)$ perceived that it can improve clinical teaching.

Conclusion: WATCH demonstrated valid, reliable, feasible, and acceptable results for assessment of teaching of medical doctors and it can be used for providing feedback and rewarding teachers who excel in teaching.
\end{abstract}

Key Words: Clinical teaching, Validity, Reliability, Feasibility, Medical students, Residents, Doctors.

How to cite this article: Haider SI, Gondol KM, Tariq M, Bari MF, Azam I. Reliability and Validity of WATCH: Warwick Assessment InsTrument for Clinical TeacHing. J Coll Physicians Surg Pak 2020; 30(06):633-637 https://doi.org/10.29271/jcpsp.2020.06.633.

\section{INTRODUCTION}

Clinical teaching, also known as bedside teaching, is a significant component of the learning and teaching in medicine. ${ }^{1}$ If a clinical teaching session is well planned and delivered effectively, it can enhance learning. However if not, it can raise a number of problems related to teaching and learning, including lack of critical thinking, analytical reasoning, passive learning, limited feedback and reflection. ${ }^{2,3}$

Correspondence to: Dr. Sonia Ijaz Haider, Department of Educational Development, Faculty of Health Sciences, The Aga Khan University, Karachi, Pakistan

E-mail: sonia.i.haider@gmail.com

Received: May 14, 2020; Revised: June 17, 2020; Accepted: June 26, 2020

DOI: https://doi.org/10.29271/jcpsp.2020.06.633
In the medical profession, doctors are responsible to teach junior trainees, and as they are increasingly involved in teaching, it is important to assess their teaching skills. ${ }^{4}$ Evidence indicates that in addition to doctors, postgraduate trainees / residents are involved in teaching activities. ${ }^{5}$ During their training, doctors are required to undertake a detailed assessment to determine their clinical competence; ${ }^{6}$ however, in terms of teaching, no comprehensive assessment is conducted to determine their teaching effectiveness. ${ }^{7}$ Effective clinical teaching is a challenging task and is influenced by a number of common problems, such as lack of clear objectives, focus on factual recall, inadequate feedback, and lack of opportunity for reflection and discussion.

In Pakistan, doctors and residents are facing similar problem as many regions of the world in formal teaching activities; and presently, no formal structured method is in place to 
assess their teaching abilities. ${ }^{8}$ Therefore, the need arises to assess clinical teaching so that efforts can be undertaken to facilitate teachers by providing feedback, and rewarding teachers who excelinteaching.

Thus, the aim of the current study was to determine the reliability and validity of WATCH: Warwick Assessment insTrument for Clinical teacHing among teaching doctors in Pakistan. The development and testing of WATCH has been previously published; ${ }^{9}$ however, its reliability, validity, feasibility, acceptability and educational impact have not been explored among doctors working within Pakistan.

\section{METHODOLOGY}

The current research study was cross-sectional and completed from September 2018 to August 2019. The instrument, WATCH, consisted of 15 items and each item was supplemented with a rating scale. The ethical institutional committee approved the study. Data collection was facilitated by the CPSP. Informed consent was obtained from all participants and participation was voluntary. All postgraduate trainees enrolled in FCPS and MCPS programmes were asked to rate the teaching ability of their teachers using WATCH. Participants were also required to complete a semi-structured 5-item questionnaire to determine feasibility, acceptability and educational impact of the administered instrument. It was an online assessment, which was administered by the College of Physicians and Surgeons (CPSP), Pakistan from September 2018 to August 2019. All the trainees completed the assessment with constant reminders and follow-ups. Only those trainees, who left their training or took a break from their training for a specified period of time, did not complete the assessment.

Data was analysed using SPSS software. For data analysis, frequencies and percentages of countries, states/provinces and cities of institutes by number of enrolled students was generated. Similarly, frequencies and percentages of gender, specialty, residency year and on different items were also generated. Inter-item correlations of 15 items were computed and Cronbach's Alpha was also reported, including Friedman test, in order to observethe scores across multiple conditions. The Hotelling's $T^{2}$ test was used to test whether the answers provided by the study participants to the questionnaire were equal. Factor analysis of these 15 items with factor coefficients using PCA were also generated. Extraction of factors were done using explained variations and Eigen values. The criteria of factor extraction was Eigen value of greater than and equal to one. A p-value of less than $5 \%$ was taken as significant. Feasibility was calculated by time taken to complete the instrument; whereas, acceptability and educational impact were determined by eliciting participants' responses to the five semi structured questions.

\section{RESULTS}

A total of 6,268 doctors from different specialties and sub-specialties participated in the study. Among them, 3,427 (54.7\%) were males and 2841 (45.3\%) were females. The majority 6,218
(99.2\%) of the participants were from Pakistan, followed by Nepal $27(0.4 \%)$, Kingdom of Saudi Arabia 10 (0.2\%), and lastly Ireland $8(0.1 \%)$. Postgraduate trainees were in different years of training and specialties. The majority of the residents were from year III, 2,294 (36.6\%), followed by year II, 1,234 (19.7\%), year IV, 989 (15.8\%) and finally, year V, 917 (14.6\%). The greater number of the residents were from medicine 889 (14.2\%), followed by obstetrics and gynecology 808 (12.9\%), surgery $720(11.5 \%)$ and pediatrics 624 (10\%).

All the participants answered the 15 items of the instrument. More than $80 \%$ of the students ranked the instrument from good to excellent on different items. Eight items received excellent rating in regard to teaching, and included the following items:

A) Q02: Communicates effectively with trainees; B) Q03: Maintains polite and considerate attitude with trainees; C) Q04: Expresses enthusiasm towards teaching and learning; D) Q05: Teaches concepts and skills in an organised manner; E) Q12: Demonstrates professional and ethical conduct; F) Q13: Avoids favouritism, criticism and discrimination; G) Q14: Remains up to date with knowledge of developments in the field; H) Q15: Is a good role model for trainees.

Following eight excellent rating items, seven received good rating and included the following items:

A) Q01: Promotes active engagement of trainees during learning; B) Q06: Demonstrates clinical competence (sound analytical, diagnostic, therapeutic and reasoning skills) appropriate for the stage of training; C) Q07: Adjusts teaching to learning needs of trainees; D) Q08: Demonstrates appropriate use of teaching aids and resources (powerpoint, flipcharts, paper handouts etc); E) Q09: Provides regular feedback to trainees about their performance; F) Q10: Stimulates reflective skills among students; G) Q11: Is able to teach in diverse settings (bedside, operating theatre, wards) and involves patients in teaching, if relevant).

Inter-item correlation ranged from 0.61 to 0.81 , indicating that there is good correlation among all items (Table I). A very strong value of Cronbach's Alpha (0.975) was observed with significant difference in the mean scores of different items (Friedman's Chi-Square $=4285.54 ; p<0.001$ ). Similarly the results from the Hotelling's $T^{2}$ test ( 21598.871 with $F=185.249$, $d f=14,2654$; $p<0.001$ ) indicated that the mean values of the responses of different questions in the instrument was statiscally different implying that the participants showed different approaches to answer the items and that the responses were reliable (Table II). Factor analysis indicated only one factor, which accounted for 73.97 of the total variance of the 15 items (Table III).

In terms of feasibility, majority $5,831(93 \%)$ of the participants indicated that it was easy to complete the instrument and most of the participants 3,975 (63.4\%) took less than 5 minutes to complete the instrument. In addition, majority 5,562 (88.7\%) of the participants indicated that completing the instrument was not time consuming. 
Table I: Inter-item correlation matrix.

\begin{tabular}{|l|c|c|c|c|c|c|c|c|c|c|c|c|c|c|}
\hline & Q01 & Q02 & Q03 & Q04 & Q05 & Q06 & Q07 & Q08 & Q09 & Q10 & Q11 & Q12 & Q13 & Q14 \\
\hline Q02 & .795 & 1.000 & & & & & & & & & & & & \\
\hline Q03 & .677 & .736 & 1.000 & & & & & & & & & & & \\
\hline Q04 & .790 & .745 & .679 & 1.000 & & & & & & & & & & \\
\hline Q05 & .772 & .747 & .667 & .782 & 1.000 & & & & & & & & & \\
\hline Q06 & .765 & .739 & .668 & .765 & .816 & 1.000 & & & & & & & & \\
\hline Q07 & .783 & .765 & .685 & .775 & .803 & .811 & 1.000 & & & & & & & \\
\hline Q08 & .701 & .674 & .604 & .702 & .720 & .735 & .777 & 1.000 & & & & & & \\
\hline Q09 & .721 & .709 & .606 & .712 & .720 & .725 & .761 & .751 & 1.000 & & & & & \\
\hline Q10 & .766 & .736 & .659 & .761 & .773 & .783 & .800 & .757 & .798 & 1.000 & & & & \\
\hline Q11 & .744 & .723 & .650 & .752 & .770 & .769 & .776 & .701 & .713 & .779 & 1.000 & & & \\
\hline Q12 & .711 & .725 & .736 & .721 & .731 & .736 & .738 & .669 & .686 & .741 & .759 & 1.000 & & \\
\hline Q13 & .629 & .663 & .718 & .630 & .646 & .647 & .671 & .593 & .621 & .654 & .643 & .719 & 1.000 & \\
\hline Q14 & .675 & .668 & .633 & .685 & .708 & .713 & .689 & .630 & .629 & .687 & .709 & .721 & .651 & 1.000 \\
\hline Q15 & .747 & .759 & .731 & .747 & .767 & .756 & .765 & .682 & .692 & .751 & .759 & .778 & .723 & .768 \\
\hline
\end{tabular}

Table II: ANOVA with Friedman's test.

\begin{tabular}{|c|c|c|c|c|c|c|}
\hline & & Sum of squares & df & Mean square & $\begin{array}{l}\text { Friedman's } \\
\text { Chi-square }\end{array}$ & Sig \\
\hline \multicolumn{2}{|c|}{ Between people } & 93371.777 & 6267 & 14.899 & & \\
\hline \multirow{3}{*}{ Within people } & Between items & $1705.277^{\mathrm{a}}$ & 14 & 121.805 & 4285.542 & $<0.001$ \\
\hline & Residual & 33212.457 & 87738 & .379 & & \\
\hline & Total & 34917.733 & 87752 & .398 & & \\
\hline \multicolumn{2}{|l|}{ Total } & 128289.510 & 94019 & 1.365 & & \\
\hline
\end{tabular}

Table III: Factor analysis: Total variance explained.

\begin{tabular}{|l|l|l|l|l|l|l|}
\hline \multirow{2}{*}{ Component } & \multicolumn{3}{|l|}{ Initial Eigen values } & \multicolumn{3}{l|}{ Extraction sums of squared loadings } \\
\cline { 2 - 7 } & Total & \% of Variance & Cumulative \% & Total & \% of Variance & Cumulative \% \\
\hline 1 & 11.096 & 73.973 & 73.973 & 11.096 & 73.973 & 73.973 \\
\hline 2 & .646 & 4.307 & 78.280 & & & \\
\hline 3 & .419 & 2.792 & 81.071 & & & \\
\hline 4 & .402 & 2.677 & 83.749 & & & \\
\hline 5 & .287 & 1.912 & 85.661 & & & \\
\hline 6 & .284 & 1.890 & 87.551 & & & \\
\hline 7 & .272 & 1.814 & 89.365 & & & \\
\hline 8 & .240 & 1.600 & 90.965 & & & \\
\hline 9 & .229 & 1.526 & 92.491 & & & \\
\hline 10 & .209 & 1.392 & 93.883 & & & \\
\hline 11 & .201 & 1.338 & 95.220 & & & \\
\hline 12 & .192 & 1.280 & 96.500 & & & \\
\hline 13 & .179 & 1.194 & 97.694 & & & \\
\hline 14 & .174 & 1.159 & 98.852 & & & \\
\hline 15 & .172 & 1.148 & 100.000 & & & \\
\hline Extraction Method: Principal component analysis. & & & & \\
\hline
\end{tabular}


In terms of acceptability, 5,733 (91.5\%) of the participants indicated that it is an acceptable method of assessment. In terms of educational impact, most 5,694 (90.8\%) of the participants agreed that the use of the instrument will improve their clinical teaching.

\section{DISCUSSION}

The aim of the present study was to validate a clinical teaching instrument (questionnaire) among doctors in Pakistan. This instrument, WATCH, was validated in England, United Kingdom, to measure clinical teaching of postgraduate trainees; ${ }^{9}$ however, in order to be used for assessment of clinical teaching, it is required to be validated in the context to be used to determine its relevance. ${ }^{10}$

The findings of the present study indicate that all the items of the instruments can be used to assess clinical teaching among doctors in Pakistan. Overall participants rated 8 items as excellent in terms of assessment of clinical teaching of their teachers. These items are related to overall conduct, communication skills, and professional attitude of their clinical teachers. The remaining 7 items were rated good pertaining to effective delivery of clinical teaching. It would have been ideal if participants had also rated them as excellent, but the rating of 'good' indicates that teachers need to work on their teaching skills in order to promote effective teaching. This is not surprising because doctors are not trained to be teachers, they are trained to be doctors. ${ }^{11}$ They are not required to undertake any formal teaching certification or course to be able to comprehend the effective teaching strategies. In their professional career of becoming a doctor, they learn teaching through ad-hoc methods. ${ }^{12-14}$ Although professionalism, communication skills and ethics are taught formally in the medical school, ${ }^{15,16}$ no teaching strategies are taught and the need for it is well supported by the existing literature. ${ }^{17,18}$

The results of inter-item correlation indicated internal consistency of all the items - that is the scores of the individual items of the survey are measuring a single concept only which is clinical teaching. The reliability coefficient Cronbach Alpha was 0.975 , further confirming the reliability of the instrument used. This is similar to the findings of the WATCH, which was used in England in which the reliability coefficient was $0.92 .^{9}$

Factor analysis was used to determine the construct validity, which showed that there is only one factor which the instrument is measuring and that factor is clinical teaching only. This corroborates the findings of the earlier study, in which clinical teaching was among the three factors found on the WATCH. ${ }^{9}$

Majority of the participants found the instrument as a feasible method to assess clinical teaching because it takes less than 5 minutes to complete it. In a busy clinical setting in which patient care is priority to clinical teaching, anything which takes more than 5 minutes is less likely to be used. This is confirmed by existing evidence in which clinical teaching instru- ments which have demonstrated valid and reliable findings, but those which took more than 5 to 10 minutes were not used by the stakeholders. ${ }^{19}$

Moreover, a greater number of the participants found WATCH an acceptable method of assessment. Clinical teaching assessment can be challenging to measure when residents and physicians are working in busy environment. The fact that $90.8 \%$ and above indicated its acceptability, it shows that it can be used easily in a busy clinical setting.

In addition, most of the participants also agreed in terms of perceived educational impact of the instrument. The implication is that the long term aim is to use this instrument as a formative method of assessment of postgraduate trainees; ${ }^{20}$ and therefore, the results of present study and existing literature $^{9,21}$ indicate that in absence of formal training course, this instrument can be used to facilitate clinical teachers in acquiring effective clinical teaching skills, thorough assessment, and feedback.

\section{CONCLUSION}

Warwick Assessment insTrument for Clinical teacHing (WATCH) can be used for assessment of clinical teaching in Pakistan. The instrument has demonstrated valid, reliable, feasible and acceptable results and has potential for positive educational impact on doctors in Pakistan. It can be used for providing feedback and rewarding teachers who excel in teaching.

\section{FUNDING:}

The study was funded by Higher Education Commission of Pakistan, 5221/Sindh/NRPU/R\&D/HEC.

\section{ETHICAL APPROVAL:}

The ethical institutional committee approved the study.

\section{PATIENTS' CONSENT:}

Informed consents were obtained from all participants and the participation was voluntary.

\section{AUTHORS' CONTRIBUTION:}

SIH, KMG: Substantial contribution to conception, drafting and final approval.

MT: Substantial contribution to acquisition, drafting and final approval.

MFB: Substantial contribution to interpretation, drafting and final approval.

IA: Substantial contribution to data analysis, drafting and final approval.

\section{CONFLICT OF INTEREST:}

Authors declared no conflict of interest.

\section{REFERENCES}

1. Peters $M$, Ten Cate O. Bedside teaching in medical education: $A$ literature review. Perspect Med Educ. 2014; 3(2): 76-88.

2. Hoffman KG, Donaldson JF. Contextual tensions of the clin- 
ical environment and their influence on teaching and learning. Med Educ 2004; 38(4):448-54.

3. Dolmans DH, Wolfhagen $I H$, Heineman $E$, Scherpbier AJ. Factors adversely affecting student learning in the clinical learning environment: A student perspective. Educ Health (Abingdon) 2008; 21(3):32.

4. Council GM. The Doctor as Teacher. London 1999.

5. Edwards JC, Friedland JA, Bing-You R. Residents teaching skills. New York: Springer Publishing; 2002.

6. GMC. Tomorrow's doctors: General Medical Council; 2003. Available from: http://www.gmc-uk.org/education/ under graduate/tomorrows_doctors.asp.

7. Zabar S, Hanley K, Stevens DL, Kalet A, Schwartz MD, Pearlman E, et al. Measuring the competence of residents as teachers. J Gen Int Medicine 2004; 19(5):530-3.

8. Siddiqui FG, Shaikh NA. Challenges and Issues in medical education in pakistan. J Liaquat Uni Med Health Sci 2014; 13(3):91-2.

9. Haider SI, Johnson N, Thistlethwaite JE, Fagan G, Bari MF. WATCH: Warwick assessment instrument for clinical teaching: Development and testing. Med Teach 2015; 37(3):289-95.

10. Al Ansari A, Strachan K, Hashim S, Otoom S. Analysis of psychometric properties of the modified SETQ tool in undergraduate medical education. BMC Med Educ 2017; 17(1):56.

11. British, Medical, Association. Doctors as Teachers. BMA Marketing \& Publications 2006.

12. Seabrook MA. Medical teachers' concerns about the clinical teaching context. Med Educ 2003; 37(3):213-22.

13. Khan IA. Bedside teaching-making it an effective instruc-tional tool. J Ayub Med Coll Abbottabad 2014; 26(3):286-9.

14. Ah-Kee EY, Scott RA, Shafi A, Khan AA. How can junior doctors become more effective teachers? Adv Med Educ Pract 2015; 6:487-8.

15. Jagzape TB, Jagzape AT, Vagha JD, Chalak A, Meshram RJ. Perception of medical students about communication skills laboratory (csl) in a rural medical college of central india. J Clin Diagn Res 2015; 9(12):JC01-4.

16. Mahajan R, Aruldhas BW, Sharma M, Badyal DK, Singh T. Professionalism and ethics: A proposed curriculum for undergraduates. Int J Appl Basic Med Res 2016; 6 (3):157-63.

17. Busari JO, Scherpbier, AJJA. Why residents should teach: A literature review. J Postgrad Med 2004; 50(3):205-10.

18. Boursicot K, Etheridge L, Setna Z, Sturrock A, Ker J, Smee S, et al. Performance in assessment: Consensus statement and recommendations from the Ottawa conference. Med Teach 2011; 33(5):370-83.

19. Beckman TJ, Lee MC, Mandrekar JN. A comparison of clinical teaching evaluations by resident and peer physicians. Med Teach 2004; 26(4):321-5.

20. AlHaqwi Al, Taha WS. Promoting excellence in teaching and learning in clinical education. J Taibah University Med Sci 2015; 10(1):97-101.

21. Nejatdarabi $H$, Amini M, Yarahmadi J, Bikineh $P$, Kaveh $M$, Gholampoo H. Validity and reliability of the Persian version of WATCH questionnaire in assessing the clinical learning environment. Biomed Res 2018; 29(17):3356-61. 